\title{
ARTÍCULOS
}

\section{UN BREVE RECORRIDO POR LA HISTORIA DEL PARTIDO DEL TRABAJO DE ESPAÑA (PTE)}

\section{A short tour by the history of The Partido del Trabajo de España (PTE)}

\section{Ernesto M. Díaz Macías}

Universidad de Cádiz ernesto.mdiazmacias@gmail.com

Orcid: 0000-0001-9969-7781

\section{Cómo citar este artículo/Citation:}

Ernesto M. Díaz Macías, "Un breve recorrido por la historia del Partido del Trabajo de España (PTE)", Hispania Nova, 19 (2021): 389 a 420.

DOI: https://doi.org/10.20318/hn.2021.5886
Copyright: (C) HISPANIA NOVA es una revista debidamente registrada, con ISSN 1138-7319 y Depósito Legal M 9472-1998. Los textos publicados están -si no se indica lo contrario- bajo una licencia Reconocimiento-Sin obras derivadas 3.0 España de Creative Commons. Puede copiarlos, distribuirlos y comunicarlos públicamente siempre que cite su autor y la revista y la institución que los publica y no haga con ellos obras derivadas. La licencia completa se puede consultar en: http://creativecommons.org/licenses/by-nd/3.0/es/deed.es
Resumen: la historia de la izquierda revolucionara en la Transición española ha sido marginada por la historia oficial. El Partido del Trabajo de España (PTE) fue la organización comunista más grande, pero su historia es desconocida. En este artículo intentamos recuperar apuntes relacionados con su historia.

Palabras clave: Transición, partido político, comunismo, ruptura democrática, oposición democrática.
Abstract: the revolutionay left's history of the Spanish Transition has been marginalised by the oficial history. The Partido del Trabajo de España (PTE) was the biggest comunist organization, but his history is unknown. This article tries to recover some notes related to its history.

Keywords: Transition, political party, comunism, democratic breakdown, democratic opposition. 


\section{INTRODUCCIÓN}

La historia oficial de la Transición se generó a costa de marginar al conjunto de movimientos, partidos y organizaciones a la izquierda del PCE. El objetivo fundamental de esta perspectiva fue atribuir a las élites políticas que dirigieron la Transición los méritos exclusivos de construir una democracia, aunque sea, limitada.

Este consenso ideológico tiene una traducción académica en el terreno de la historia bien concreta: obviar el papel de los protagonistas que, desde la movilización y la autoorganización popular, fueron clave en la conquista de la democracia limitada que se inaugura tras la Transición.

Este olvido selectivo se ha cebado más si cabe con los partidos revolucionarios $y$ de los 60 y 70. El mismo caso podemos apreciar en casos cercanos, como puede ser el olvido de las organizaciones revolucionarias en el Portugal de la Revolución de los Claveles ${ }^{1}$. Es la concreción de la consigna tan conocida de "la historia la hacen los vencedores" que en nuestro caso se traduce en "quienes forjaron la visión canónica de la Transición tendieron a relegar estos proyectos alternativos en el relato histórico del periodo",

Frente a ese olvido selectivo, que tiene mucho de ideológico y poco de académico, se han puesto en funcionamiento esfuerzos específicos para recuperar esa parte del protagonismo olvidado. En esta línea van trabajos que pretenden narrar la historia de la Liga Comunista Revolucionaria (LCR) ${ }^{3}$ o la historia del Partido del Trabajo de España (PTE).

Este artículo pretende hacer un balance general del Partido del Trabajo de España (PTE): de sus orígenes y desarrollo, de sus aciertos y errores así como de la aportación general al periodo que nos ocupa. Las subdivisiones del artículo se han definido en función de las que pensamos que representan mejor las distintas fases de esta organización.

\footnotetext{
${ }^{1}$ El trabajo de Varela es un buen ejemplo de recuperación de la memoria popular y revolucionaria tras un proceso de amnesia institucional y académica. Ver Raquel Valera, História do Povo na Revolução portuguesa: 1974-1975. (Lisboa: Bertrand, 2014).

2 Julio Pérez Serrano, “Orto y ocaso de la izquierda revolucionaria en España (1959-1994)" en Rafael Quirosa-Cheyrouze (coord.): Los partidos en la Transición. Las organizaciones políticas en la construcción de la democracia en España. (Madrid: Biblioteca Nueva, 2013), p. 250.

${ }^{3}$ Martí Caussa y Ricard Martínez y Muntada, Historia de la Liga Comunista Revolucionaria. (Madrid: La oveja roja, 2014).
} 
Una primera nota. Los orígenes del PTE hay que buscarlos en la constitución del Partido Comunista de España (internacional) (PCE (i)). Pero éste es a su vez es una transformación de una escisión del Partido Comunista de España (PCE) denominada “Grupo Unidad”. Desde aquí arranca nuestro estudio.

\section{EL “GRUPO UNIDAD” ¿ ¿UNA RADICALIZACIÓN IMPORTADA?}

Entre 1955 y 1956 tienen lugar una serie de discusiones en el seno del Partido Comunista de la Unión Soviética (PCUS) con repercusión internacional. El XX Congreso del PCUS se culmina en febrero de 1956 renovando la confianza por la "coexistencia pacífica" con el capital mundial ${ }^{4}$. De nuevo, los partidos comunistas oficiales quedaban ligados a una orientación conciliadora en sus respectivos países.

Esta reafirmación creó tensiones con varios agentes comunistas internacionales siendo el más representativo el creado con el Partido Comunista de China (PCCh). Aunque ya desde los primeros años de la Revolución China se acumulaban diferencias importantes entre la dirección del PCUS y la dirección del $\mathrm{PCCh}^{5}$ no es hasta la fecha del XX Congreso y la desestalinización cuando Mao impulsa una crítica sistemática al PCUS y a la URSS de forma pública ${ }^{6}$. Desde entonces, y sobre todo desde inicios de la década de los 60, Mao y el PCCh intentan presentarse como una continuidad del marxismo-leninismo ${ }^{7}$ frente al revisionismo que representa la teorización de la coexistencia pacífica. De este modo, nace el maoísmo como corriente internacional del comunismo.

El PCCh trabajará por tener secciones en cada país del mundo como contrapeso a la influencia mundial del PCUS. Pero más allá de los representantes "oficiales" del maoísmo en cada país, la realidad es que en cada sitio proliferan por lo general

\footnotetext{
4 Julio Pérez Serrano, “Orto y ocaso de...” op. cit. pp. 250-251.

${ }^{5}$ Véase León Trotsky, La Internacional Comunista después de Lenin. (Madrid: Akal, 1977, o Pierre Rousset, La revolutión chinoise. Tome 1: La Deumième révolution chinoise et la formation du projet maoiste. Amsterdam, Cuadernos del IIRF/IIRE, 1986.

6 Brenda Rupar, "El debate chino-soviético y la emergencia del maoísmo como corriente política diferenciada en el Movimiento Comunista Internacional”. Historia Contemporánea, 57 (2018).

${ }^{7}$ Hablamos de un marxismo-leninismo que intenta crear una continuidad lógica y natural entre Marx, Lenin, Stalin y Mao. Algo que no ha compartido una parte importante de la izquierda desde hace años pero que por entonces era una referencia natural dentro del campo maoísta.
} 
numerosos grupúsculos sectarizados y contrapuestos entre ellos ${ }^{8}$ que se reclaman maoístas. El impacto específico del maoísmo en los años 60 y 70 no puede explicarse si no es por la radicalización juvenil y obrera, que tiene en mayo de 1968 su año de referencia.

El Estado Español no es un caso aislado. En las filas del propio PCE (que representaba el "comunismo oficial", el ligado al PCUS y a la URSS) las divisiones prochinas se hacen sentir desde mediados de los años 60 . Y primeramente en el seno del Partido Socialista Unificado de Cataluña (PSUC).

Como en todos los casos, el surgimiento de dichas disidencias tiene protagonistas con nombres y apellidos. En éste caso será Manuel Valverde (bajo el pseudónimo de "Miguel"), un estudiante enviado desde Francia para recomponer el PSUC en Barcelona ${ }^{9}$, junto con “Andrés”, quienes comienzan a impulsar debates en el seno del PCE/PSUC poniendo en cuestión la orientación general del partido.

Su esfuerzo controbuyó a hacer resurgir el partido_que previamente había sido diezmado por la represión franquista. Sin embargo, la misma dinámica de masas activa en el Estado Español desde 1962 radicaliza a ambos. En la mayoría de los debates que se producen entre 1962 y 1967 la dirección juvenil del PSUC dinamizada por Valverde parece situarse a la izquierda de la dirección del conjunto del Partido.

Las diferencias fueron creciendo y enquistándose. Los críticos con la dirección moderada del PSUC y del PCE se agruparon cada vez más en torno a Valverde. Y la ruptura definitiva entre ambos acontece en 1967, cuando el PCE publica la "Declaración de abril" ${ }^{10}$ en la que renuncia a una ruptura revolucionaria en beneficio de un pacto con sectores del régimen por concesiones democráticas. Este documento no hacía sino reafirmar la coexistencia pacífica a la que se había sumado el PCE desde la celebración del Comité Central el verano de 1956, “el corolario español del XX Congreso del

\footnotetext{
${ }^{8}$ Miguel Cardina, Margem de certa maneira. O maoísmo em Portugal: 1964-1974. (Lisboa: Tinta da China, 2011).

9 José Luis Martín Ramos, "Los orígenes de una nueva formación” en Pan, trabajo y libertad. Historia del Partido del Trabajo de España. (Barcelona: El viejo topo, 2012), p. 27.

${ }^{10}$ Ibidem, p. 30.
} 
PCUS"11. De la ruptura nace el "Grupo Unidad" como grupo orgánicamente independiente.

Valverde y su grupo identificaron estas nuevas tesis como una renuncia a la revolución socialista en beneficio de una estrategia de conciliación con un sector del Régimen franquista. O lo que es lo mismo, una aplicación de las tesis de la “coexistencia pacífica” al marco del Estado Español.

Frente al revisionismo que representaban las nuevas tesis de Carrillo, Valverde intentó representar la renovación revolucionaria a la que la dirección del PCE y del PSUC habrían renunciado. Por ello, el Grupo Unidad termina rompiendo con ambas organizaciones entre abril y mayo de $1967^{12}$. Una nueva etapa se iniciaba para el grupo que veía en la Revolución Cultural China un nuevo horizonte internacional para la renovación del comunismo revolucionario.

Es difícil atribuir sólo a Valverde y a Andrés la autoría exclusiva de la ruptura. La radicalización juvenil y obrera internacional de los años 60 afectó a buena parte de los Partidos Comunistas oficiales de todo el mundo. Por tanto, la escisión del Grupo Unidad no puede considerarse simplemente como una importación de los conflictos del movimiento obrero internacional. Es sobre todo fruto de una radicalización mundial que acontece a caballo entre las dos décadas. La misma radicalización juvenil y obrera que aconteció en países cercanos como Francia atravesó a una parte del movimiento obrero del Estado Español y al movimiento estudiantil ${ }^{13}$. En este caso la radicalización del movimiento juvenil y obrero cristalizó en esta ruptura a finales de los años $60^{14}$.

El grupo recién creado sumará en el verano de la ruptura a un grupo estudiantil junto a otro proveniente del PSUC, aunque este último tendrá escaso recorrido con los militantes que formarán el PCE (i) ${ }^{15}$.

\footnotetext{
${ }^{11}$ Julio Pérez Serrano, "Estrategias de la izquierda radical en el segundo franquismo y la Transición (1956-1982" en Chaput, Marie Claude; Pérez Serrano, Julio (eds.): La Transición española. Nuevos enfoques para un viejo debate. (Madrid: Biblioteca Nueva. 2015), p. 99.

${ }^{12}$ Marta Campoy Fernández, "El PTE en la Transición. La ilusión por la ruptura (1975-1977)" en Pan, trabajo y libertad. Historia del Partido del Trabajo de España. (Barcelona:, El viejo topo, 2012), p. 237.

${ }^{13}$ Sobre la importancia del movimiento estudiantil en la izquierda revolucionaria véase Miguel Gómez Oliver, "El movimiento estudiantil español durante el franquismo (1965-1975)" en Revista Crítica de Ciências Sociais, $\mathrm{n}^{\circ}$ 81, 2008, p. 107.

${ }^{14}$ La dirección del PCE no asistió inmóvil frente al proceso de ruptura. El mismo Carrillo intentó mediar con la dirección juvenil sin éxito.

${ }^{15}$ Julio Pérez Serrano, “Orto y ocaso de...” op. cit. p. 261.
} 


\section{EL SECTARISMO MAOISTA DEL PRIMER PCE (I)}

En diciembre de 1967 comenzaron los preparativos para la constitución del nuevo partido. Unos primeros pasos que inicialmente sólo cuenta con núcleos en Barcelona, Sevilla, Zaragoza y Madrid.

Aunque el grupo ya venía denominándose PCE (i) desde los primeros meses de la ruptura, no es hasta diciembre de ese año cuando comienzan a intentar elaborar una línea propia $\mathrm{y}$ organizar sistemáticamente en todos los ámbitos un partido independiente.

Los primeros pasos de definición de una línea política revolucionaria parecen haberse dado no sin dificultad. El grupo de jóvenes universitarios y obreros que rompe con el PCE parece haber reaccionado a la ruptura con unas posiciones izquierdistas cercanas al "tercerismo" o "Tercer Periodo" de la III Internacional ${ }^{16}$ mezclado con una hipótesis estratégica en línea con la ruptura del Régimen franquista mediante la lucha armada. Esta es la idea original en torno a la que se articula el conjunto de trabajos de intervención militante y que se traducía de forma concreta en pequeñas operaciones armadas como pueden ser robos a bancos o similares. Una línea ultrasectaria criticada a posteriori por antiguos militantes ${ }^{17}$.

Todas las hipótesis de trabajo del nuevo partido se acompañaban con un telón de fondo de claro tinte maoísta en la que no se reparaba en los elogios a la "Gran Revolución Cultural Proletaria China [que] ha supuesto en primer paso fundamental hacia la internacional de nuevo tipo", así como al mismo "camarada Mao Tse Tung"18.

Esta hipótesis estratégica define la orientación del PCE (i) frente al resto de partidos. En el caso del PCE (i) el principal enemigo será su organización madre, el PCE, junto al Frente Obrero de Cataluña (FOC). Esta competición, junto con la crisis

\footnotetext{
${ }^{16}$ Esta posición fue teorizada por la III Internacional en el VI Congreso de la IC de 1928 en la que se analizaba la inminencia de un proceso revolucionario internacional y decretaba la preparación de todos los PCs para la ocasión. Entre algunas de sus perspectivas entraba el rechazo de la unidad con el resto de partidos de izquierda y la denuncia de la socialdemocracia como principal enemigo.

17 José Antonio Errejón, “El Partido del Trabajo de España” en Viento Sur, 115 (2011).

18 Mundo Obrero, "Vanguardia revolucionaria y vanguardia contrarrevolucionaria", $1^{\circ}$ quincena de noviembre de 1968.
} 
parcial que vivían organizaciones como el FOC le brindó al PCE (i) la oportunidad de incorporar a militantes procedentes de estas filas que jugarán posteriormente un papel central en el desarrollo del PTE, como puede ser el caso de Manuel Gracia Luño.

Pero los primeros compases no se dan solamente a nivel de definición de las relaciones con el resto de los partidos. La intervención en el seno del movimiento obrero era uno de los debates estructurales de un partido revolucionario y pasaba en aquel periodo fundamentalmente por definir el papel del PCE (i) en relación a las Comisiones Obreras $(\mathrm{CCOO})^{19}$. Para el recién fundado PCE (i), el grueso de las CCOO, dirigidas en su mayor parte por militantes o simpatizantes del PCE, no podía representar las aspiraciones revolucionarias del movimiento obrero. Consecuentemente, se organizaron agrupaciones propias de militantes y simpatizantes denominadas Comisiones Obreras Revolucionarias $(\mathrm{COR})^{20}$.

Esta orientación aislaba sobre la práctica a la organización del grueso de la clase trabajadora y del movimiento obrero organizado. Las CCOO a nivel nacional expresaban la unidad de un movimiento obrero parcialmente espontáneo que veía la división con recelo. El resultado después de varios años manteniendo la actividad de las COR solo agrupa a militantes del PCE (i) y algunos simpatizantes.

Un mayor acierto se tuvo con el lanzamiento en 1970 de las Juventudes Universitarias Revolucionarias (JUR), uno de los frentes juveniles del PCE (i), que supo canalizar una parte de la radicalización juvenil que bullía por entonces. A través de este frente de intervención se unieron a la organización estudiantes universitarios que formarían parte de la dirección del partido a los pocos años. Junto a esta iniciativa se impulsaron a mediados de 1971 dos frentes más de intervención juvenil adicionales: la Joven Guardia Roja (JGR) y las Juventudes Revolucionarias de Bachillerato (JRB) ${ }^{21}$. Las tres_convivirán como organizaciones independientes vinculadas al PCE (i) hasta 1973, fecha en la que se fusionarán organizativamente. La intervención juvenil fue

\footnotetext{
${ }^{19}$ No hay que olvidar que por entonces las CCOO eran organismos unitarios de lucha y no el sindicato oficial que terminó siendo. Esta realidad marca el debate en el seno del PCE (i) sobre las mismas.

${ }^{20}$ Mundo Obrero, “Existe el partido de la clase obrera?”, diciembre de 1968.

${ }^{21}$ Mundo Obrero Rojo, "La Joven Guardia Roja y las Juventudes Universitarias Revolucionarias”, agosto de 1971.
} 
siempre una de las claves del crecimiento del PCE (i)/PTE como organización, gozando de buena intervención sobre todo en los medios universitarios ${ }^{22}$.

Estos son los ejes fundamentales que estructuraron la primera etapa de la vida del recién constituido PCE (I). La tensión de la clandestinidad y de las operaciones militantes, el aislamiento con respecto al grueso del movimiento obrero con la teorización de las COR junto con una vida democrática interna caracterizada por el autoritarismo de Valverde ${ }^{23}$ deterioró gravemente la vida interna de la organización. Durante los primeros años, la vida interna del PCE (I) parece estar atravesada por duros conflictos politicos que no solían tener buena salida.

\section{REORIENTACIÓN ESTRATÉGICA: HACIA UNA PERSPECTIVA FRENTE- POPULISTA}

Esta orientación aislacionista es solo temporal. En los primeros años de la década de 1970 se inicia una reflexión interna de calado. Una reflexión marcada por una profunda autocrítica que termina por imprimir un giro estratégico al conjunto del partido $^{24}$.

Este giro parece propiciado-por el cambio de responsabilidades centrales que se produce tras el arresto de Valverde a inicios de la década de los 70. Los intentos de dirección de la organización desde la cárcel son contestados por la dirección del PCE (i) con una ruptura definitiva con su fundador. Tras este hecho, Valverde romperá con la organización para fundar el "Partido Comunista de España (internacional)-línea proletaria".

Desde la ruptura con su fundador se comienza un nuevo periodo para el PCE (i), un periodo en el que habrá una nueva bancada liderando el partido: personas como Eladio García Castro, Manuel Armenta Espejo y Manuel Gracia Luño ${ }^{25}$ serán algunos

\footnotetext{
${ }^{22}$ Alberto Carrillo-Linares, "Movimiento estudiantil antifranquista, cultura política y transición política a la democracia" en Pasado y Memoria. Revista de Historia Contemporánea, 5 (2006).

${ }^{23}$ José Luis Martín Ramos, “Los orígenes...” op. cit., p. 59.

${ }^{24}$ A pesar de que la militancia pretende rectificar errores pasados, la organización había conocido en el periodo anterior un crecimiento militante constante pero limitado.

25 En concreto Manuel Gracia parece haber dado saltos de altura en muy poco tiempo. En meses es proyectado desde sus responsabilidades como responsable de la zona norte de (Barcelona: hasta llegar a la
} 
de los nombres de ese nuevo protagonismo. Pero es un nuevo protagonismo que acompañaba el sentir general en el conjunto del partido. El grueso de sus militantes estaba de acuerdo con la autocrítcia que comenzaba a circular en el partido y estaban dispuestos a una reorientación profunda.

Los esfuerzos por teorizar un nuevo rumbo van a materializarse al poco tiempo. Es interesante analizar cómo el primer paso en el viraje de rumbo fue tomar conciencia de las propias limitaciones e impulsar un curso de formación interna como paso previo para discutir una línea política adecuada en el contexto que se encontraban.

El ciclo de formación se encuadra en una conferencia de cuadros que se realiza en la primavera de 1972. Esta es la fecha que marca el inicio del giro político. Eladio García jugará el rol de ponente. El ciclo tenía una parte de aprendizaje de fundamentos básicos y otra de análisis de la realidad española. En relación al segundo eje, la formación social española se entiende como una realidad marcada fundamentalmente por un capitalismo con cierto grado de desarrollo. Al desarrollo de las fuerzas productivas corresponderá el hecho de "que la revolución pendiente en España era la revolución socialista" 26 .

Esta revolución ahora se teoriza como algo a conquistar por etapas ${ }^{27}$ siendo la primera de estas la conquista de la democracia popular, una etapa que "no habría que confundir con la democracia «burguesa»" 28 , sino como la primera etapa de la lucha por la dictadura del proletariado ${ }^{29}$. Este eje como veremos será profundamente problemático para el PCE (i) pues intenta equilibrar dos aspectos de difícil conciliación en caso de que no hubiera una irrupción popular.

Esta primera etapa debía inaugurarse, por tanto, con la unidad y lucha de todos los agentes que estuvieran dispuestos a la ruptura democrática del Régimen. La fórmula de trabajo que parece avanzarse es la de la constitución de un amplio frente popular

\footnotetext{
dirección central del partido. La lectura más probable es la necesidad que tiene la dirección en esta coyuntura de cuadros centrales en condiciones de generar orientación política. Por tato, y bajo el lenguaje de la época, es probable que fuera cooptado para funciones de dirección.

${ }^{26}$ José Luis Martín Ramos, “Los orígenes...”, op. cit., p. 79.

27 Esta no es la concepción del primer PCE (i) que teorizaba la revolución socialista sin etapas intermedias.

28 Julio Pérez Serrano, "Estrategias de la izquierda...” op cit., p. 106.

${ }^{29}$ Sobre la dictadura del proletariado, 1975, AT., Fondo Partidos y Organizaciones Políticas, Partido del Trabajo de España, https://s3.eu-west-

3.amazonaws.com/webpte/Hemeroteca/Hacia+el+Socialismo/HaciaI6.pdf
} 
antifascista que agrupara a los partidos y movimientos de la clase trabajadora, así como a los sectores de la burguesía que tuvieran un interés en una ruptura del Régimen.

La consecuencia inmediata de estas reflexiones para el conjunto del PCE (i) es el cambio de la política de relaciones con el resto de partidos. De un aislamiento autorreferencial se pasa a una colaboración partidaria interclasista lo más amplia posible dentro del esquema del frente popular. En este nuevo panorama la relación con el PCE cambia. Este deja en el corto plazo de ser el enemigo principal para convertirse en un aliado táctico para los objetivos de la etapa.

Aquí radica quizás alguno de los elementos más limitantes del PCE (i): su hipótesis estratégica. Si en el desarrollo de los acontecimientos se desligaban las reivindicaciones democráticas y socialistas ¿Qué garantizaba que el conjunto del proceso no se frenará en las conquistas democráticas? ¿Acaso no había una vía reformista para conseguir esas conquistas democráticas? Volveremos más adelante a esta pregunta.

El nuevo encuadre político no puede ceñirse exclusivamente a un reordenamiento de las relaciones con otros partidos. La hipótesis política de trabajo del frente popular debía traducirse necesariamente a nivel de intervención social. Esto es lo que explica que el PCE (i) termine por abandonar definitivamente la hipótesis de trabajo de las COR en beneficio de una intervención honesta en el seno de las $\mathrm{CCOO}^{30}$. Desde entonces, el PCE (i) apuesta por la integración en las CCOO allá donde existen o impulsándolas allá donde no tienen realidad ${ }^{31}$.

Junto a este viraje político se comienzan a articular discusiones políticas a todos los niveles de la organización para ir configurando una suerte de pre-comité central. En la etapa anterior la militancia actuaba en un partido caracterizado por un vacío de órganos de dirección efectivos.

La reorientación era sustancial en términos de orientación estratégica. Tal viraje, impreso en pocos meses, no podía más que traducirse en tensiones con el sector de la organización que seguía reconociéndose en la etapa anterior. Los nuevos cuadros dirigentes, representantes de la nueva línea, deben encarar tensiones crecientes con el sector que previamente había sido liberado para poner en marcha los elementos

\footnotetext{
${ }^{30}$ Manuel Gracia Luño, "La fundación del nuevo partido: estrategia, táctica y línea de masas" en Pan, trabajo y libertad. Historia del Partido del Trabajo de España. (Barcelona: El viejo topo, 2012), p. 89.

${ }^{31}$ Mundo Obrero Rojo, "Las Comisiones Obreras en Madrid”, agosto de 1972, pp. 8-9.
} 
centrales del primer PCE (i): oposición frontal al PCE, lucha armada, las COR... E1 cambio de orientación hacia un frente popular significaba para ellos el fin de su liberación política. Y aunque es posible que sus diferencias con la nueva dirección no tuvieran relación directa con la desaparición de sus puestos de trabajo sino con un debate estratégico real, la coincidencia temporal es exacta. Después de perder el Congreso de 1973, el grupo de Alfonso Rey Guntin abandona la organización, consumando la segunda ruptura con importancia en la organización ${ }^{32}$.

El proceso de reorientación se pone en marcha en lo restante de 1972 para ir hacia un Congreso Constituyente del PCE (i) en abril de $1973^{33}$. El congreso cuenta con delegados, pero han sido elegidos desde la cúpula de la dirección y no por un proceso de elección por la base. Algo en ese momento achacable_a las condiciones de clandestinidad a las que obligaba el Régimen y que tenía incidencia en los métodos organizativos de los partidos revolucionarios ${ }^{34}$.

Este congreso no marcará un nuevo viraje sino que profundizará y sistematizará la orientación marcada el año anterior: frente popular que inaugure un Gobierno Provisional en ruptura con el Régimen, etapa democrática como fase previa a la revolución socialista, unidad social del proletariado en CCOO, el papel de las naciones sin Estado en el proceso (fundamentalmente Cataluña, Euskadi y Galicia) ${ }^{35}$... Lo más curioso en las tesis congresuales es el cierto divorcio que se intuye entre una perspectiva política de frente popular y una perspectiva social de frente único ${ }^{36}$.

En este congreso, las referencias internacionales se refuerzan. EE. UU. queda retratado como el principal enemigo internacional. La URSS es retratada como un bloque derrotado y transformado que ya no es socialista y que estaba en consonancia

\footnotetext{
32 Julio Pérez Serrano, “Orto y ocaso de...” op. cit. p. 262.

${ }^{33}$ Es cuanto menos curioso que no es hasta seis años después de su inicio de actividad en 1967 cuando el PCE (i) lanza su congreso de Constitución. Esto denota un posible desprecio por la vida interna democrática de la etapa anterior.

34 Josepa Cucó i Giner, "La izquierda revolucionaria y la Transición. Dinámicas y procesos”, Debats, 1 (2018), p. 15.

${ }^{35}$ Resoluciones sobre la línea política, 1973, AT., Fondo Partidos y Organizaciones Políticas, Partido del Trabajo de España https://s3.eu-west3.amazonaws.com/webpte/Documentos/PCE(i) + Org + Cen/Resoluciones + Congreso $+\mathrm{de}+\mathrm{Constituci} \% \mathrm{C} 3 \%$ B3n.pdf

${ }^{36}$ Este divorcio de perspectiva es explícito al considerar el trabajo en las CCOO un trabajo de frente único mientras se habla explícitamente de frente popular antifascista en lo tocante a las relaciones partidarias y la intervención en organismos unitarios antifranquistas, espacios interclasistas.
} 
con la caracterización hecha por el maoísmo sobre la reconstrucción del capitalism en la URSS y su transformación en potencia "social-imperialista"37. La claudicación de la URSS marca las nuevas relaciones internacionales con los que serían los nuevos referentes del marxismo y de la revolución: China, Albania, Corea...

De las decisiones prácticas más trascendentales del congreso cabe señalar la incorporación a la Asamblea de Cataluña $(\mathrm{AC})$, el primer organismo unitario del movimiento antifranquista, que llevaba funcionando desde 1971. La composición de la $\mathrm{AC}$ entraba perfectamente dentro de los esquemas de frente popular antifascista que propugnaba el PCE (i).

Junto a su participación en este frente el PCE (i) parecía consciente de que no podía representar a la totalidad del marxismo-leninismo en las fronteras del Estado Español. Por ello, se declaraba partidario de la unificación de todo el movimiento m-1 existente, aunque no será capaz de unificarse con el Movimiento Comunista (MC) y sólo en última hora con la Organización Revolucionaria de los Trabajadores (ORT).

El congreso se cierra con la elección de la dirección que revalidará a los cuadros centrales que han protagonizado el giro político. Nos referimos a los ya mencionados Eladio García, Manuel Armenta y Manuel Gracia.

Algunas de las tesis congresuales les permitirá situarse en buena posición en el momento político. En el año 73 comienza la crisis económica en el Estado Español ${ }^{38}$ y comienza a gestarse un auge huelguístico que coincide con la entrada del partido en las CCOO.

Por su parte, la entrada en la AC no fue inmediata. El inicio de las relaciones constata una división del organismo a dos niveles: un nivel de dirección denominado Comisión Coordinadora de Fuerzas Políticas de Cataluña (CCFPC) ${ }^{39}$ y la propia AC. La primera era un organismo cerrado cuya función era la negociación con el régimen en caso de apertura de posibilidades sobre avances democráticos. La segunda era un espacio abierto a las organizaciones que pretendía servir de eje movilizador para eventos

\footnotetext{
${ }^{37}$ Brenda Rupar, "El debate chino-soviético...”, op. cit., p. 566.

${ }^{38}$ Ramón Adell Arguilés, "Transición y transiciones permanents" en La lucha por la ruptura democrática en la Transición. (Madrid: Asociación por la memoria histórica del Partido del Trabajo de España, 2010), pp. 25-26.

39 La composición inicial era Esquerra Republicana de Catalunya (ERC), PSUC, Front Nacional de Catalunya (FNC), Moviment Socialista de Catalunya (MSC) y Unió Democrática de Catalunya.
} 
puntuales. El PCE (i) se verá rápidamente excluida de la primera pero incluida en la segunda.

Desde entonces, el PCE (i) se tomará la construcción de la AC como una prioridad política. En la AC mostrará las coincidencias programáticas, pero también una diferencia clave: el reconocimiento del derecho de autodeterminación para Cataluña sin reducirlo al restablecimiento del Estatuto de $1932^{40}$.

A nivel práctico el PCE (i) intentó dinamizar la AC ligándola a la movilización obrera, así como al impulso de su extensión geográfica y la inclusión de más organizaciones $^{41}$. Parece que el objetivo fuera un crecimiento y maduración de la AC que permitiera un desbordamiento político y organizativo de las estrechas perspectivas de negociación arribista que tenía la CCFPC. De hecho, el mismo auge de la movilización que comenzaba a tomar cuerpo constituía unos mimbres favorables para las perspectivas del PCE (i). La negociación controlada por la que opta el PCE-PSUC se vió dificultada por el auge del protagonismo popular mientras que las propuestas de ligar la $\mathrm{AC}$ a las luchas en auge tuvieron buena acogida. Esto se traduce en un aumento de influencia del PCE (i) en el interior del organismo unitario.

En septiembre de 1973 tiene lugar la unificación de las tres ramas de intervención juvenil del PCE (i): las JUR, las JRB y la JGR se integran en esta última bajo las siglas de Joven Guardia Roja de España (JGRE) ${ }^{42}$, una fusión que ayudaría a consolidar la fuerza de la organización en el terreno estudiantil.

La radicalización crece. La separación del Jefe de Estado de la figura de Jefe de Gobierno que se realiza en 1973 se contesta con el asesinato de Carrero Blanco por parte de ETA. E1 PCE (i) hará una lectura negativa de dicho acontecimiento al reforzar al sector más duro del Régimen.

Tras la muerte de Carrero toma las riendas Arias Navarro con pretensiones de representar al ala reformista del Régimen. El conjunto de su programa es conocido como "Espíritu del 12 de febrero" en el que estaban presentes las siguientes iniciativas:

\footnotetext{
${ }^{40}$ Intervención ante la Comisión Permanente de la Asamblea de Cataluña, 1973, AT., Fondo Partidos y Organizaciones Políticas, Partido del Trabajo de España, https://webpte.s3.eu-west3.amazonaws.com/Documentos/PCE(i)+Catalunya/Intervenci $\% \mathrm{C} 3 \% \mathrm{~B} 3 \mathrm{n}+\mathrm{ante}+\mathrm{la}+\mathrm{Comisi} \% \mathrm{C} 3 \% \mathrm{~B} 3 \mathrm{n}+\mathrm{Per}$ manente+de+la+Asamblea+de+Catalu\%C3\%B1a+(biling\%C3\%BCe).pdf

${ }^{41}$ Manuel Gracia Luño, "La fundación...”, op. cit., p. 114.

${ }^{42}$ Manifiesto y bases de la Joven Guardia Roja, 1973, AT., Fondo Partidos y Organizaciones Políticas, Partido del Trabajo de España, https://webpte.s3.eu-west-3.amazonaws.com/Documentos/JGRE++ Org + Cen/Manifiesto $+\mathrm{y}+$ Bases + de + la + JGRE + octubre+1973.pdf
} 
una ley de asociaciones, una ley sindical que abría parcialmente el sindicalismo franquista oficial y una reforma del régimen local.

El PCE (i) interpretó estas iniciativas como tímidas reformas para aislar a los sectores rupturistas de la oposición. Algo que el propio Navarro no va a conseguir pero que su sucesor, Suárez, gestionará con mayor inteligencia realizando pocos cambios programáticos.

Casi al mismo tiempo, el conjunto del movimiento obrero mundial debe hacer frente a la fatídica noticia del golpe de Estado en Chile ${ }^{43}$. El PCE (i) hace una lectura propia sobre los límites de la transición pacífica al socialismo que había teorizado la Unidad Popular (UP) en aquel país. El contrapunto optimista lo representará el impulso definitivo del fin de la dictadura portuguesa el 25 de Abril de $1974^{44}$, lo que sin duda sirvió como elemento estimulador del movimiento obrero en el Estado Español, a pesar de haber sido infravalorado como element de análisis ${ }^{45}$.

El 9 de julio de 1974 se constata el empeoramiento de la salud de Franco y se consuma la sucesión en la persona de Juan Carlos de Borbón. La sucesión directa desde las manos de Franco dificultaba la imagen democrática que querían imprimir al nuevo monarca. Junto a esto, las movilizaciones en auge en 1974 se contestan por parte del Régimen con una brutal represión policial. Esto descartaba a Navarro como figura que pudiera dirigir la evolución reformista del régimen.

Un acontecimiento importante va a coger a traspié al PCE (i): la presentación el 30 de julio de 1974 por parte del PCE de la Junta Democrática de España (JDE) ${ }^{46}$. Su fundación no contó ni con la AC (organismo unitario previamente existente) ni con el PCE (i). Es una iniciativa del PCE para retomar el protagonismo público, así como constituir un organismo unitario en el que tener clara hegemonía y que contara a su vez con dimensiones estatales.

\footnotetext{
${ }^{43}$ Joán Garcés, Allende y la experiencia chilena. (Madrid: Siglo XXI, 201)3.

${ }^{44}$ Francisco Louça y Fernando Rosas, La (pen) última revolución de Europa. De la revolución de los claveles a la contrarrevolución neoliberal. (Barcelona: Sylone, 2016).

${ }^{45}$ Raquel Varela, "El «eurocomunismo» de Santiago Carrillo y la «revolución democrática y nacional» de Cunhal: la política de los partidos comunistas en el final de las dictaduras en la Península Ibérica, 19741978". https://dialnet.unirioja.es/servlet/articulo?codigo $=3312415$

${ }^{46}$ La JDE fue impulsada por el PCE, el Partido Socialista Popular (PSP) y por el Partido Carlista junto con personalidades individuales.
} 
La dirección del PCE (i) reacciona inicialmente de forma negativa frente al lanzamiento de la JDE. Le critica la falta de diálogo con otras fuerzas, así como la poca claridad programática sobre aspectos centrales como la autodeterminación de las naciones sin Estado o la apuesta decidida por la constitución de un Gobierno Provisional. A esto se unirá la crítica a que no exista ni una mención sobre la depuración del Estado franquista, de las fuerzas armadas, de la policía, judicatura, etc. Por todo ello, el PCE (i) se desmarca inicialmente de dicho organismo y decide no participar.

Sin embargo, para Manuel Gracia esto es ciertamente incoherente con las decisiones tomadas por el PCE (i) en Cataluña puesto que "si analizamos el antecedente de Cataluña, que de hecho era un organismo parecido [se refiere a la $\mathrm{AC}$ ], hoy no es comprensible esta actitud de la dirección del PTE por sectaria" ${ }^{47}$. Este rechazo impugnaba el apoyo a organismos amplios de corte frente populista que se había aprobado en el congreso. La participación en la AC abría un debate contradictorio sobre el frente popular a impulsar.

La misma dirección inicia reflexiones en ese sentido e irá rectificando su posición hasta la aceptación de la JDE y la petición de su entrada hacia noviembre de $1974^{48}$. Eladio García irá acompañado a París a reunirse con Carrillo para debatir su inclusión. La reunión se cierra con sintonía general sin acuerdo concreto.

Paralelamente se produce a lo largo de 1974 un auge del interés y de la movilización a favor de los derechos de las naciones sin Estado. A pesar de haber discutido políticamente desde hace mucho tiempo el tema, el PTE relanza una nueva discusión específica para mejorar su perspectiva política en este ámbito. Consecuentemente, se encarga a Manuel Gracia un texto que permita conocer el recorrido y la actualidad de la situación en el Estado Español. Este documento será discutido y asimilado por el conjunto de la militancia.

En diciembre de 1974 se constata otro fracaso de Arias Navarro. Su ley de Asociaciones es tan estrecha que algunos sectores del Régimen no tienen capacidad de legalizar sus proyectos políticos. Por su parte, el movimiento obrero y estudiantil experimenta otro impulso entre 1974 y 1975. Sin embargo, en más de un caso se evidencia el rol desmovilizador del PCE que ya a estas alturas parece sólo tener interés

\footnotetext{
${ }^{47}$ Manuel Gracia Luño, “Los movimientos...”, op. cit., p. 87.

${ }^{48}$ Por estas fechas el partido cuenta ya con una influencia importante en Madrid, Cataluña, Andalucía y Navarra.
} 
en impulsar movilizaciones para favorecer un acuerdo por arriba con los sectores evolucionistas del Régimen. Un caso paradigmático es el representado por algunas convocatorias contra el juicio del proceso 1001 que juzgaba a dirigentes conocidos de $\mathrm{CCOO}^{49}$.

En febrero de 1975 asistimos a un evento partidario central: la Conferencia que aprobará el cambio de nombre de PCE (i) a Partido del Trabajo de España (PTE). De igual forma, esta conferencia refrendará la línea política y social que el partido había puesto en marcha desde 1972. En el documento central de la conferencia ${ }^{50}$ se hace un balance positivo del conjunto del trabajo y se apuesta decididamente por la participación en la JDE.

Un elemento novedoso que va a determinar el futuro inmediato de la Transición es la recomposición de la dirección del PSOE (que se traduce en el acceso al poder interno de Felipe González al frente del mismo relevando a toda la vieja guardia) y el impulso en junio de 1975 de la Plataforma de Convergencia Democrática (PCD) ${ }^{51}$. Este será el organismo "unitario" del PSOE frente al Régimen. ¿Qué lleva al PSOE a constituir casi en solitario un nuevo espacio antifranquista? El PSOE no se había incorporado a la Junta Democrática debido al rol dirigente que jugaba dentro el PCE y por ello_funda la nueva plataforma para balancear fuerzas.

El PTE analizaba negativamente el impulso de la $\mathrm{PCD}^{52}$, por generar división en el movimiento antifranquista, así como por haberse constituido con un programa mucho más moderado que la de la propia JDE. Su impulso de forma independiente se realizaba con el fin de posicionar al PSOE con ventaja en relación al PCE. Por tanto, la confrontación inicial entre ambos organismos estaba servida.

Pero tras unas semanas la lucha entre las dos plataformas va dando paso en octubre del 75 hacia un entendimiento ecléctico que subordinaba cada vez más al PCE a

\footnotetext{
${ }^{49}$ Marta Campoy Fernández, “El PTE en...” op. cit., p. 165.

${ }^{50}$ Primera Conferencia del Partido del Trabajo de España, 1975, AT., Fondo Partidos y Organizaciones Políticas, Partido del Trabajo de España, https://s3.eu-west3.amazonaws.com/webpte/Hemeroteca/Hacia+el+Socialismo/HaciaI5.pdf

51 Su composición inicial incluía al PSOE, al PNV, al Movimiento Comunista de España (MCE) e Izquierda Democrática (ID), entre otros.

52 El Correo Del Pueblo, “Las Juntas Democráticas, en el camino a la libertad”, 9 (1975).
} 
la orientación más moderada del PSOE. Aun así el PTE interpretó el primer acercamiento con optimismo ${ }^{53}$.

Aunque la movilización presiona a las partes a un entendimiento, el acuerdo entre ambas se salda con numerosas concesiones programáticas por parte del PCE. E1 nacimiento de la Coordinadora Democrática (CD o Platajunta) se realiza con una imposición casi completa por parte de la PCD y por tanto del PSOE. Por no decir que parece que las partes parecían confiar poco en la plataforma para algo más que como trampolín para iniciar negociaciones con el sector reformista del Régimen. La CD parecía nacer así como una demostración de fuerza para mejorar la posición de tal o cual partido para conseguir su legalización, no ya como el frente de lucha antifascista que proclamaba el PTE ${ }^{54}$.

A pesar de esto, el PTE celebra públicamente su lanzamiento sin darse cuenta del verdadero significado de la fusión: una marginación de las posiciones del PTE así como una claudicación definitiva de muchos sectores la oposición ante los ofrecimientos de reforma del régimen que excluía las perspectivas de ruptura que propugnaba el PTE. Esta decantación era evidente con la posición de la CD en relación a las movilizaciones populares que se afirmaban, por ejemplo, en diciembre de 1975. Con esta perspectiva, la fusión de la JDE y de la PDC solo podría realizarse con una mayor moderación del PCE ${ }^{55}$.

A pesar de ello, el PTE pide su inclusión en la CD sin mucha crítica. El PTE se amoldaba a la situación sin una perspectiva clara de trabajo participando acríticamente lo que algunos han denominado "las rebajas de la oposición política" ${ }^{56}$ : un punto de llegada que terminará avalando la reforma de la dictadura, pero que partía de una impugnación revolucionaria del conjunto del capitalismo español.

\footnotetext{
${ }^{53}$ El Correo Del Pueblo, "Comentario de la Redacción de «El Correo del Pueblo»”, nº 19 (1975).

${ }^{54}$ Esto lo prueban dos datos más allá de la moderación programática: la obligación de disolver los organismos unitarios territoriales y la obligación de decidir la inclusión de la CD en movilizaciones por unanimidad. El voto en contra de uno suponía veto a iniciativas movilizadoras. Ambas propuestas están diseñadas a la medida de impulsar acuerdos por arriba con el Régimen.

${ }^{55}$ Otro ejemplo que viene al caso es la matanza de Vitoria el 3 de marzo de $1976^{55}$. En vez de movilizar consecuentemente, Felipe González se reúne secretamente con Fraga para valorar la posible legalización del PSOE con la nueva Ley de Asociaciones que se estaba gestando desde enero de ese mismo año por Arias Navarro.

${ }^{56}$ Editorial, "Las rebajas de la «oposición política»" en La Transición en Cuadernos de Ruedo Ibérico. (Barcelona: Backlist, 2011),
} 
Un mes antes, en noviembre de 1975, muere Franco reactivando un ciclo de movilizaciones. Con su muerte, se abre una coyuntura política en la que se conjugan "movilización social provocada por la muerte de Franco, la incertidumbre de los primeros pasos de la monarquía y la negociación de convenios colectivos" ${ }^{\text {"57. }}$.

El balance de este periodo quedaría incompleto si no analizáramos algunos límites del PTE y de algunos errors que tuvieron lugar en la conferencia de cuadros que dio pie al cambio de nombre. Junto a esta decisión se toman otras apuestas como el reforzamiento del trabajo sectorial más allá del movimiento obrero. Hablamos de un trabajo específico en el movimiento feminista, barrial, ejército, etc. Se constituyeron secretariados específicos para reforzar la intervención en dichos sectores.

Esta decision representaba un gran avance del PTE con respecto a varias organizaciones revolucionarias de la década. Pone de relieve la comprensión de que no todo el movimiento obrero se organizaba en las CCOO y que existían formas de politización y radicalización más allá del movimiento sindical. Ya existía cierta comprensión de esta realidad con el lanzamiento de los frentes juveniles a lo que se agrega ahora nuevos avances.

Sin embargo, y a nuestro entender, esta comprensión del trabajo sectorial iba acompañado de un límite bastante evidente: el trabajo social en estos frentes no adquirió la forma de frentes unitarios, sino más bien de frentes partidarios amplios donde entraban en relación los militantes del PCE (i) con simpatizantes de la línea política del sector que fuera.

No son pocos los ejemplos de este nuevo divorcio de perspectivas. Por ejemplo, el lanzamiento de la Unión Democrática de Soldados (UDS) como iniciativa del partido en enero de 1976, cuando la Unión Militar Democrática (UMD) llevaba constituida desde 1974. Podría justificarse atendiendo a los obvios problemas de clandestinidad al intentar establecer un trabajo dentro de la UMD. Pero esta interpretación no es válida ya que no es la única decisión tomada en este sentido. En 1976 se lanza también la Asociación Democrática de Jóvenes (ADJ) que no era más que un frente amplio de las Joven Guardia Roja de España (JGRE), transformación de un frente partidario previo denominado Movimiento Democrático de la Juventud (MDJ).

\footnotetext{
${ }^{57}$ Ferrán Gallego, El mito de la Transición. (Barcelona: Crítica, 2008, p. 334).
} 
La misma orientación toma cuerpo respecto al movimiento feminista con el impulso de la Asociación Democrática de la Mujer (ADM), integrado fundamentalmente por militantes del PTE y de la ORT. Un giro en lo social que va delimitando una nueva posición política que difería de los previamente teorizados frentes populares antifascistas a nivel político y frente único en el movimiento obrero. ¿Por qué se se decidía impulsar procesos unitarios a nivel del movimiento obrero, pero en el resto de sectores se impulsaban frentes partidarios? Sea como fuere parece que esta orientación se va a reforzar entre 1976 y 1977 para configurar los elementos de la nueva etapa del PTE.

\section{DE LA INFLUENCIA FRENTE-POPULISTA DE MASAS AL AISLACIONISMO MODERADO}

Desde julio de 1976 el Régimen inicia un cambio de rumbo determinante. El gobierno de Arias Navarro se da por agotado y Juan Carlos nombra a Suárez nuevo presidente del gobierno. Este lanza una ofensiva que, con pocos cambios programáticos a los de Arias Navarro, va a traducirse en una vía plausible de auto reforma del Régimen al tener mayor capacidad de integración de los principales elementos de la oposición antifranquista.

Tras su nombramiento, Suárez comienza a reunirse con varios protagonistas de la oposición para valorar los posibles pasos a dar. Muchas de las organizaciones comienzan a exponer públicamente las posibilidades de entendimiento con Suárez para pactar una auto reforma del Régimen. Muchas de estas organizaciones comienzan a hacer todo tipo de maniobras o declaraciones por fuera de la CD buscando salidas individuales a su legalización. Este efecto era el deseado por Suárez que pretendía una integración de los elementos más moderados del movimiento antifranquista y aislar a los movimientos y organizaciones revolucionarias.

Este escenario era inédito hasta entonces. "El inmovilismo político del régimen durante la década de 1960 había favorecido el trabajo de la izquierda revolucionaria" ${ }^{\text {. }}$. Este mismo contexto es el que había permitido al PTE conciliar temporalmente una

\footnotetext{
${ }^{58}$ Pérez Serrano, “Estrategias de la izquierda...” op cit., p. 109.
} 
salida democrática y socialista, una perspectiva de ruptura conviviendo con alianzas interclasistas. Pero desde el momento en el que cada vez más sectores comenzaban a negociar su legalización sin poner en cuestión el conjunto del Régimen, las demandas democráticas y socialistas se presentaban cada vez más en forma de disyuntiva y no en forma de equivalentes. De esta forma, el PTE fue crecientemente neutralizado por la estrategia reformista, igual que el conjunto de la izquierda revolucionaria. Se inicia desde entonces una "deriva posibilista" ${ }^{59}$. Una neutralización que el propio PTE estimuló, puesto que desde el primer momento de la ofensiva se mostró abierto al diálogo con el Gobierno ${ }^{60}$ a través de los organismos unitarios, reconociendo a Suárez como interlocutor válido. Todas estas concesiones se realizan en uno de los años de mayor movilización social que vió en el invierno de $1976^{61}$ la cima de las movilizaciones en el periodo de la Transición, dando paso a un proceso de desmovilización escalonado.

A pesar de la desorientación general, algunas iniciativas populares consiguen victorias parciales desde la calle. Así hay que leer el decreto de amnistía parcial que emite el nuevo gobierno tras las jornadas por la Amnistía política de julio de 1976.

En el verano esta ofensiva se concreta no sólo con reuniones personales, sino con la publicación de ejes programáticos para impulsar un pacto por la auto reforma. En agosto del 76 Suárez anunciaba un referéndum para finales de año que apostara por unas cortes bicamerales elegidas por sufragio universal, legalización de algunos partidos (excluyendo a los comunistas, republicanos y Carlistas) y un referéndum para validar dichas propuestas. El referéndum se celebró el 15 de diciembre de 1976 bajo unas condiciones completamente antidemocráticas, con los partidos ilegalizados y con una persecución de aquellos que pedían el no o la abstención, en la que se encuadraba el PTE. Organizado a la medida del "sí", el referéndum triunfa y dota de una nueva legitimidad al proceso impulsado por Suárez.

El proyecto de Suárez pretendía de nuevo "dividir a la oposición destruyendo el proyecto unitario de $\mathrm{CD}$, desmantelar los movimientos sociales y políticos, aislar a los

\footnotetext{
${ }^{59}$ Ibídem, p. 112.

${ }^{60}$ Pérez Serrano, “Orto y ocaso de...” op. cit. p. 263.

61 Emmanuel Rodríguez López, Por qué fracasó la democracia en España. (Madrid: Traficante de sueños, 2015), p. 33.
} 
partidos de la clase obrera y ganarse el apoyo de las fuerzas más vacilantes" ${ }^{262}$. Pero expresado de esta forma parecería que la división del movimiento antifranquista viene solo del exterior, cuando realmente la parte más moderada de este movimiento llevaba tiempo buscando la integración en un escenario democrático posfranquista, sea inaugurado por una reforma o por una ruptura democrática.

Un paso más de esta ofensiva lo tenemos con la legalización de la mayor parte de los partidos hacia febrero en 1977. El PTE parece apostar con pocos compañeros de viaje por una negociación unitaria con el Régimen mientras que el resto corre individualmente a pactar su legalización. Así pasó este mismo mes con la legalización del PSOE y del PCE. El mantenimiento del resto de partidos en la ilegalidad era responsabilidad directa de ambos partidos que, a estas alturas, poco parecía importar una hipotética salida unitaria de la oposición a la situación.

Esta ofensiva de Suárez desorienta al PTE y comienza a desmontar sobre la práctica sus perspectivas de frente popular antifascista por la ruptura democrática del Régimen. ¿Con quién impulsar unitariamente una ruptura democrática si las organizaciones con mayor influencia corrían a pactar con Suárez apostando por mantener una parte del Régimen franquista? La presencia y el impulso de la CD por parte del PTE ¿No hacían el juego al PSOE y al PCE? ¿No les reforzaba en su estrategia de pactos arribistas? ¿No obligaba todo el reposicionamiento de la parte moderada del movimiento antifranquista a un reencuadre general de las perspectivas del PTE? Para Pérez Serrano la transformación de fondo que experimentaba el PTE se debe a que el avance de la reforma propició que muchas organizaciones revolucionarias dieran por bueno las conquistas democráticas parciales ${ }^{63}$. Una interpretación similar realiza Ferrán Gallego hablando sobre la posición del PTE en las elecciones de 1977 que revelarían que este partido aceptó varios meses más tarde lo que el PCE y el PSOE habían interiorizado desde hace meses atrás: el fracaso de la ruptura ${ }^{64}$.

Lejos de hacer un balance profundo del momento (algo que el PTE había hecho en otras ocasiones en el pasado) parece que, sobre la práctica, lo que toma forma es una creciente subordinación del conjunto de la actividad a la iniciativa electoral e

\footnotetext{
${ }^{62}$ Campoy Fernández, “El PTE en...”, op. cit., p. 184.

${ }^{63}$ Pérez Serrano, "Estrategias de la izquierda...” op cit., p. 113.

${ }^{64}$ Gallego, op. cit., p. 515.
} 
institucional como única salida para sobrevivir. Una subordinación de la que no se librará tampoco la JGRE que, desde 1974 y bajo nuevas formas, cada vez intervenía con mayor esfuerzo en el movimiento político en detrimento del sectorial ${ }^{65}$.

Un fenómeno muy parecido va a tomar cuerpo en julio de 1976 con la recomposición de las perspectivas sindicales. Y centralmente nos referimos a la Asamblea de CCOO. Esta se reúne el 1 de julio del 77. Había una clara diferencia entre las hipótesis de futuro del PTE (hacer de CCOO la base de una central única de trabajadores ${ }^{66}$ ) y la del PCE (hacer de CCOO un sindicato que compartiera espacio con otras corrientes como UGT, USO...). Manuel Gracia y Manuel Armenta fueron enviados a negociar su posición un mes antes (junio) con el PCE.

En esa reunión el PCE dejó clara cuál sería su apuesta: dejar tiempo de impulso a la UGT y una legalización posterior de CCOO como sindicato oficial. Las perspectivas de un acuerdo en torno a una central única quedaban descartadas. Así se llega a la asamblea de CCOO en la que se escenifica la derrota de la ponencia minoritaria que agrupaba al PTE, al Partido Comunista de Unificación (PCU) y la ORT tendente a la formación de la central única.

Aun así, CCOO quedaba como sindicato oficial, pero también como gran central de trabajadores con capacidad de unir a una parte importante del proletariado. A pesar de esta realidad, el buró político del PTE decide a mediados de agosto de 1976 la ruptura con $\mathrm{CCOO}$ en beneficio del impulso de "sindicatos unitarios". Las rupturas se van sucediendo territorialmente y los sindicatos unitarios componiéndose por abajo durante meses. Para noviembre de 1976 se impulsa la primera Confederación de Sindicatos Unitarios de Trabajadores (CSUT) ${ }^{67}$. La excepción es la Ejecutiva del PTE en Cataluña que apuesta por mantenerse en CCOO por constatar que sería más unitario

\footnotetext{
${ }^{65}$ Se puede ver entre otras decisiones con la creación de Asambleas Democráticas juveniles. Mundo Obrero Rojo, "Las asambleas democráticas se extienden por todo el país", 28 (1974). O el trabajo con las JJSS y la UJCE en relación a la carta de derechos juveniles en la redacción de la Constitución hasta su expulsión en febrero de 1978. El País, "La Joven Guardia Roja, separada del Consejo de la Juventud", 1978.

${ }^{66}$ El Correo del Pueblo, "Libertad sindical y unidad sindical", 29 (1976), p. 2.

${ }^{67}$ Primera Conferencia Estatal de la Confederación de Sindicatos Unitarios de Trabajadores, 1976, A.T., Fondo Movimiento Obrero/Organizaciones Sindicales, Confederación de Sindicatos Unitarios de Trabajadores https://s3.eu-west3.amazonaws.com/webpte/Documentos/Movimiento+obrero+y+sindicalismo/CSUT/Confederal/Intervenc

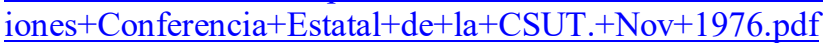


que el lanzamiento del CSUT, aunque al final termina aceptando disciplinadamente la decisión de la dirección central.

¿Se analizaba mal la situación o se apostaba decididamente por un frente sindical afín al partido? Lo que sí es un hecho es que la ORT rompe con el CSUT por las diferencias con el PTE en su primer encuentro, algo que podría clarificar la segunda hipótesis en un contexto que aún permite cierto optimismo político. De hecho, uno de los argumentos para la ruptura de CCOO es la hegemonía del PCE en la misma.

Aunque podría interpretarse como una orientación globalmente errónea por contribuir a su parcial aislamiento, el inicio de la CSUT tiene un éxito inicial importante en varios puntos de nuestra geografia ${ }^{68}$. Entre ellos en Andalucía con el impulso del Sindicato de Obreros del Campo (SOC) ${ }^{69}$ que rápidamente obtiene unos niveles de afiliación importantes pues se habla de cuarenta mil afiliados en toda Andalucía.

Esta orientación tendrá eco en la primera cita electoral de la Transición. En efecto, a lo largo de 1977 el PTE sigue desdibujando las características centrales de su cultura política. Pero lejos de reordenar su posicionamiento, parece que en lo sucesivo mantendrá una hipótesis estratégica que combina moderación (frente popular por la ruptura democrática) conjugado con un aislamiento social en el plano organizativo (continuando su orientación de frente partidario que habíamos visto anteriormente en sustitución de frentes únicos) ${ }^{70}$.

A lo largo de 1977 la decisión central que contribuirá a un mayor aislamiento del PTE en la línea que describimos es la presentación en solitario a las elecciones generales de marzo de 1977. Con el mantenimiento de la prohibición de muchos partidos políticos, la mayoría de la izquierda revolucionaria se presenta a los comicios bajo "marcas blancas". En el caso del PTE se traduce en el impulso de las candidaturas del Frente Democrático de Izquierdas (FDI) en el Estado Español, mientras que en Cataluña se presenta con un acuerdo con ERC bajo el nombre de Esquerra de Catalunya (EC).

\footnotetext{
${ }^{68}$ En esta línea van algunas de las interpretaciones de aquellas personas que han escrito la historia del PTE. Véase Ramón Franquesa Artés, "Estabilización del nuevo régimen y autodisolución (1977-1980)" en Pan, trabajo y libertad. Historia del Partido del Trabajo de España. (Barcelona: El viejo topo, 2012), p. 287.

${ }^{69}$ El Correo del Pueblo, "Un gran paso para la clase obrera española”, 67 (1976).

${ }^{70}$ Nos referimos a moderada en relación con las organizaciones de su izquierda que habían descartado el frente popular por alianzas con la burguesía.
} 
Al menos la versión oficial de la candidatura del FDI pretendía ser un frente amplio de varias organizaciones de izquierda. Pero parece que al final el FDI, y en menor medida la EC, quedaban constituidos fundamentalmente como frentes amplios de partido que no integraba a más organizaciones que al propio PTE y a sus frentes sociales y a aliados territoriales menores. En esta línea, la CSUT, apenas constituida como "sindicato unitario", apostaba explícitamente por el apoyo al FDI ${ }^{71}$.

Las Elecciones Generales se celebraron el 18 marzo de 1977 parecen encaradas erróneamente no sólo por parte del PCE (que esperaba traducir en términos electorales una influencia social que sin duda era grande), sino también por el PTE. Es cierto que todo estaba bien preparado para que a nivel electoral hubiera un triunfo de $\mathrm{UCD}^{72}$. Pero no haber sido capaz de encontrar acuerdos amplios a la izquierda del PSOE pasa factura. Los malos resultados con relación a la dinámica social de movilización existente serán un lastre importante no sólo para el PTE, sino para el resto de la izquierda revolucionaria ${ }^{73}$.

El espacio político que el PTE intentaba conformar (recordemos, el impulso de una unidad antifascista por la ruptura, pero defendiéndola ya casi en aislamiento con respecto al resto de los "grandes de la izquierda") se iba estrechando cada vez más. Se imponía o una huida institucionalista hacia delante o una reorientación de las relaciones con las organizaciones a su izquierda (MCE, ORT, LCR...).

A pesar de haber intentado un proceso de acercamiento con el MCE, la ORT y el PCU desde 1976, prácticamente ningún esfuerzo llega a buen puerto. Sólo la unificación con el PCU en 1977 marca contratendencia ${ }^{74}$. Pero al parecer era una unificación con un grupo muy pequeño y la operación no tenía grandes aspiraciones unitarias. El gran objetivo parecía posicionarse como el más unitario de las organizaciones revolucionarias.

El grado de desorientación que hace gala en estos momentos el PTE nos lo dan dos datos. El primero es un correcto posicionamiento contra los Pactos de la Moncloa en

\footnotetext{
${ }^{71}$ Primera Conferencia Estatal de la Confederación de Sindicatos Unitarios de Trabajadores, 1976, op. cit., p. 4-5.

72 Franquesa Artés, "Estabilización del...", op. cit., p. 252.

${ }^{73}$ Historia electoral. (s.f.), en. http://www.historiaelectoral.com/e1977.html

74 Bases ideológicas y politicas del Partido del Trabajo de España, 1977, A.T., Fondo Partidos y Organizaciones Políticas, Partido del Trabajo de España. https://s3.eu-west3.amazonaws.com/webpte/Documentos/PTE+Org+Cen/Bases+PT.pdf
} 
junio de 1977. El PTE fue capaz de anticipar que lo único que podría suponer dicho acuerdo era la estabilización de determinados derechos democráticos a costa de un aumento de la precariedad de la clase trabajadora. De este modo no sólo se posicionaba a favor de los intereses de los trabajadores, sino que no hacía seguidismo de las posiciones del PSOE y del PCE, permitiéndole mantener un espacio político propio.

El segundo es un voto favorable a la Constitución de 1978 (excepto en Euskadi). ¿Era comprensible desde la hipótesis estratégica de ruptura democrática que mantenía el PTE un voto favorable a la Constitución? ¿No se renunciaba así explícitamente no sólo a la ruptura, sino también a la república o a la conquista de una democracia sin imposiciones ni continuidades del franquismo?

Es posible que dicho voto favorable tuviera por objetivo formar parte del sentir general que pretendía favorecer la integración en el proceso que se iba gestando, así como no quedar aislados del PSOE y del PCE. Sin embargo, con el voto afirmativo a la Constitución el PTE contribuía a su propio aislamiento. El PSOE y el PCE estaban en proceso de copar el conjunto de la izquierda moderada en la época. Por tanto, un posicionamiento como este solo podía contribuir al empequeñecimiento de su espacio político propio. Con más INRI cuando se realiza de forma solitaria.

A este revuelo general se une contemporáneamente la aparición de importantes tensiones entre la dirección central y la catalana en el seno del PTE. Bajo la acusación de desviaciones nacionalistas, la Ejecutiva central desplaza a determinados cuadros del partido en Cataluña y traslada desde Madrid a Cataluña a otros tantos para asegurar el control de la región. Manuel Gracia parece haber jugado un papel clave por su regreso (decidido partidariamente) a Barcelona. De hecho, es el quien dirige las negociaciones con ERC para la candidatura conjunta de marzo del 77. Es más, él mismo y no ningún militante catalán, será el candidato en la lista conjunta por parte del PTE.

Sin embargo, las tensiones se reproducirán al poco tiempo. Esta vez será una confrontación de la dirección central contra el propio Manuel Gracia, quien pretendía ser consecuente con la defensa del derecho de autodeterminación y federar el partido ${ }^{75}$, consumando fricciones entre los cuadros centrales que habían liderado históricamente el partido.

\footnotetext{
${ }^{75}$ Sobre el partido federal en Materiales de estudio y discusión para el primer congreso del Partido del Trabajo de España, 1978, A.T., Fondo Partidos y Organizaciones Políticas, Partido del Trabajo de España https://s3.eu-west-

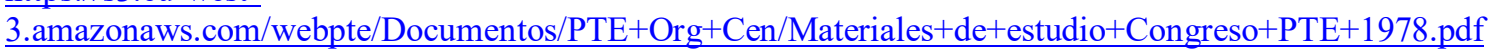


El debate tiene lugar en el Congreso del PTE de 1978. Parece que la disputa congresual la gana Manuel Gracia y el PTE en Cataluña pasa a denominarse PTC. Desde entonces y de forma creciente, el PTE comenzará a implicar esfuerzos en el proceso de removilización en clave autonomista -federalista que se va despertando en varias regiones del Estado. Uno de los elementos que mejor representa este auge es la movilización multitudinaria del 11 de septiembre de 1977 que determina el restablecimiento de la Generalitat. O el papel del PTE en la movilización del 4 de diciembre en Andalucía que se ha interpretado como hito fundamental para la aprobación de la constitución de Andalucía en Comunidad Autónoma. Estas son dos de las victorias que pueden atribuirse en parte al trabajo del PTE.

Entramos en una situación caracterizada por la moderación general del proletariado y una integración importante de gran parte de la sociedad en los acuerdos políticos que hasta ahora han tomado cuerpo. Es en este contexto en el que el PTE parece haber hecho una apuesta determinante para su futuro inmediato: para sobrevivir como organización con influencia de masas considera necesario obtener representación institucional de cualquier forma.

\section{LA APUESTA INSTITUCIONALISTA Y LA AUTODISOLUCIÓN DEL PTE}

A pesar de que seguirá implicado en numerosos frentes sectoriales, parece ser cierto que una parte importante de la militancia del PTE, así como de sus recursos políticos y materiales, se van dedicando de forma creciente a la disputa política en la que el PTE tenía menos posibilidades: el frente electoral. Conseguir representación institucional seguía siendo la máxima prioridad del partido. En 1979 serán dos las citas electorales que afrontarán: el 1 de marzo las segundas generales de la historia reciente y 3 abril las primeras elecciones municipales desde la II República.

En la primera convocatoria, el PTE se vuelve a presentar en solitario y los resultados que obtienen son parecidos, aunque mayores a los de las elecciones de 1977. El balance es de nuevo profundamente negativo. El panorama que se abre pone en riesgo la supervivencia de la organización, o así lo lee una parte importante de su dirección. 
La desorientación se salda con un nuevo salto adelante: si los resultados negativos se deben a la división de la izquierda revolucionaria, había que atajarla de forma inmediata. Se inicia un proceso de fusión en frío y muy acelerado con la ORT para presentar listas conjuntas de cara a las municipales del mes siguiente. Es un proceso que se inicia para intentar salir de las crisis en las que se encontraban ambas organizaciones: de orientación, de financiación y de representatividad al quedar fuera de las instituciones. El triunfo de la fusión "dependía de su capacidad de renovar la organización, la línea política y la dirección"76.

De esa fusión acelerada e impulsada por cálculos electorales nace el Partido de los Trabajadores (PT). Los resultados en los comicios electorales son globalmente buenos (300.000 votos y unos 400 concejales con 20 alcaldes), pero las diferencias entre las dos organizaciones, que apenas han tenido unas semanas para digerir el proceso de fusión, afloran a cada paso. La organización unificada no tardará en resentirse por el proceso acelerado de unificación que ha sido profundamente artificial.

A esto se suma el afloramiento de un problema económico de dimensiones catastróficas. Para financiar el ciclo electoral una parte importante de los cuadros se han hipotecado para conseguir recursos para las campañas. Los resultados no cubren las deudas, y se inicia una espiral de crisis de la que el partido no es capaz de salir de forma colectiva. Las salidas individuales priman sobre las colectivas haciendo imposible el mantenimiento del partido que decretará su auto disolución en una reunión celebrada el julio de 1980. Crisis partidaria que tampoco resistirán ni la CSUT ni la JGRE, disueltos ambos al poco tiempo.

\section{HACIA UNA EXPLICACIÓN HISTÓRICA DE LA AUTODISOLUCIÓN}

La historia del PTE es una de las historias más convulsas de las escritas sobre la izquierda revolucionaria española. En pocos años pasa de ser uno de los partidos más sectarizados en el terreno del Estado Español (hablamos de la primera fase del PCE (i) con Valverde a la cabeza) a girar bruscamente en los años 1972-1973 para dotar al

\footnotetext{
${ }^{76}$ Gonzalo Wilhelmi, Romper el consenso. La izquierda radical en la Transición espalola (1975-1982). (Madrid: Siglo XXI, 2016, pp. 264-265).
} 
partido de una línea y ambición de masas para terminar siendo uno de los partidos revolucionarios más moderados. Aunque hubo muchos elementos que cambiaron a lo larfo de su historia, uno que permanece a lo largo de toda su historia es la referencialidad en el maoísmo. De hecho, algunos de sus dirigentes más importantes viajaron a China para entablar diálogo directo con el $\mathrm{PCCh}^{77}$.

Desde el cambio de orientación en 1972-1973 y hasta 1976 será, ante todo, un partido con coherencia y con capacidad de influencia. Estos años son años donde algunas de sus hipótesis parecen poder cobrar relevancia como es la participación en lo que en sus esquemas era el frente popular antifascista (en la AC o en la JDE), así como poner en marcha su hipótesis de frente único en el seno del movimiento obrero (en CCOO). El crecimiento partidario por estos años, a pesar de algunas dificultades puntuales, parece sostenido. Afloran los nuevos miembros provenientes de muchas escalas: CCOO, JGRE, trabajo barrial, feminista...

Esta etapa comienza a difuminarse con la entrada en escena de Suárez. La ofensiva que comienza para atraerse a los sectores integrables en la auto reforma (PSOE, PCE, nacionalistas) y aislar al resto (PTE, ORT, LCR...) da frutos. En este periodo, coherencia no es igual a efectividad. A cada paso que da Suárez entre el 76 y el 77 desarma políticamente un poco más al PTE. En efecto, su estrategia victoriosa cierra a cada paso las perspectivas de mantener un frente popular antifascista con aspiraciones de ruptura. ¿Con quién sostener ese frente si todos los partidos de la oposición antifranquista habían sido cooptados por Suárez?

Junto al aislamiento político que propician los sectores evolucionistas del Régimen hay que recordar errores propios del PTE que contribuyeron activamente a su aislamiento: la ruptura de CCOO y la intervención en algunos movimientos sociales con ambiciones escasamente unitarias.

Junto a este proceso de aislamiento parece que el PTE hace una lectura adaptacionista del momento político entre el 77 y el 78. Si cada vez menos personas estaban por la ruptura, había que moderar las perspectivas. Eso es lo que explica el voto positivo a la Constitución en 1978 y la apuesta electoralista desde 1977. Los resultados

\footnotetext{
77 Asociación Memoria PTE Archivo de la Transición, "Eladio García Castro", Youtube, 1:44:18, https://www.youtube.com/watch?v=DgtNnIFW2yo, 56:30.
} 
de esta apuesta contrastaron profundamente con lo esperado por los miembros de la dirección, tal como afirma Manuel Armenta en una de sus entrevistas ${ }^{78}$.

Ese doble movimiento (aislamiento de un sector de masas a la vez que se moderan políticamente las posiciones estratégicas) priva al PTE de su base social propia y contribuye a reducir el espacio político que genuinamente había construido en fases previas. Es cierto que la estabilización de la nueva situación golpeó a todas las organizaciones de la izquierda revolucionaria. Pero parece que la desorientación del PTE contribuyó a reducir más su espacio político. Se privaba a sí mismo de influencia al aislarse de determinados sectores. Pero la moderación política de voto sí a la Constitución situaba al PTE en un campo político copado ya por el PSOE y el PCE y contribuía en parte a desnaturalizar la existencia del PTE.

Esto sitúa crecientemente al PTE en campo de nadie: organizaciones a su izquierda se mantenían firmes en el no a la constitución, así como en otros campos. Aunque aisladas, estas organizaciones contaban con espacio propio. Por ejemplo, la LCR. Esto explica su supervivencia por varios años. Sin embargo, el PTE intenta disputar un terreno que está ya completamente hegemonizado por el PCE y por el PSOE por lo que desde 1976 contribuye a la reducción de su propio espacio político. En palabras de Pérez Serrano, "el gran error, compartido por toda la izquierda revolucionaria, no fue abandonar la senda del PSOE y del PCE [algo que en el fondo el PTE no hizo], sino no distanciarse suficientemente de ella"79.

Había alternativas, como han indicado antiguos militantes ${ }^{80}$. Sin embargo, la desorientación política parece ser profunda. Se da un salto adelante en una estrategia electoralista de cara a los comicios del 79 que tendrá en el endeudamiento bancario personal y en la fusión en frío con la ORT los ejemplos de máxima desorientación.

Es aquí donde radica la verdadera explicación de la autodisolución del PTE. No solo eran problemas económicos o giros de grupos hacia la entrada del PSOE. Ambos movimientos son el resultado de una desorientación estratégica de calado que va

\footnotetext{
78 José Luis Molano Bravo, “Entrevista a Manuel Armenta”, Amazonaws, 36:47, septiembre 2007, https://s3.eu-west-

3.amazonaws.com/memoriadelatransicion/Memoria+oral/Entrevistas+30PTA/Manuel+Armenta+Espejo. $\underline{\mathrm{mp} 3}$, 9:10.

${ }^{79}$ Pérez Serrano, "Estrategias de la izquierda...”, op cit., p. 123.

${ }^{80}$ Ramón Franquesa Artés, “Estabilización del nuevo régimen y autodisolución (1977-1980)” en José Luis Martín Ramos (coord.), Pan, trabajo y libertad. Historia del Partido del Trabajo de España. (Barcelona: El viejo topo, 2012), p. 313.
} 
afirmándose desde 1976 y que se acelera entre 1977 y 1979. Una desorientación que acabó con el partido más importante de la izquierda revolucionaria española en la Transición.

Aprender de la historia de organizaciones como el PTE es clave para repensar el futuro de proyectos emancipadores: "Revisar este heterogéneo legado es condición inevitable para comprender la dimensión anticapitalista que tuvo en sus comienzos la lucha por la democracia y a cuantas cosas realmente posibles [...] se renunciaron en cada uno de los pactos que fueron jalonando la Transición" ${ }^{\text {81. }}$.

\section{BIBLIOGRAFÍA}

Adell Arguilés, Ramón. "Transición y transiciones permanents" en La lucha por la ruptura democrática en la Transición. 55-79. Madrid: Asociación por la memoria histórica del Partido del Trabajo de España, 2010

-- "Estabilización del nuevo régimen y autodisolución (1977-1980)" en Martín Ramos, José Luis (coord.). Pan, trabajo y libertad. Historia del Partido del Trabajo de España. 259-306. Barcelona: El viejo topo, 2012,

Asociación Memoria PTE Archivo de la Transición, "Eladio García Castro", Youtube, 1:44:18, https://www.youtube.com/watch?v=DgtNnIFW2yo.

Campoy Fernández, Marta. "El PTE en la Transición. La ilusión por la ruptura (19751977)" en Pan, trabajo y libertad. Historia del Partido del Trabajo de España. 157-270. Barcelona: El viejo topo, 2012.

Cardina, Miguel. Margem de certa maneira. O maoísmo em Portugal: 1964-1974. Lisboa: Tinta da China, 2011.

Carrillo-Linares, Alberto "Movimiento estudiantil antifranquista, cultura política y transición política a la democracia" en Pasado y Memoria. Revista de Historia Contemporánea, 5 (2006).

Caussa, Martí y Martínez i Muntada, Ricard (eds.). Historia de la Liga Comunista Revolucionaria. Madrid: La oveja roja, 2014.

Cucó I Giner, Josepa. "La izquierda revolucionaria y la Transición. Dinámicas y procesos", Debats, 1 (2018): 13-24.

Errejón, José Antonio. “El Partido del Trabajo de España” en Viento Sur 115 (2011).

Franquesa Artés, Ramón, «Estabilización del nuevo régimen y autodisolución (19771980)» en Pan, trabajo y libertad. Historia del Partido del Trabajo de España. 259-306. Barcelona: El viejo topo, 2012.

Gallego, Ferrán, El mito de la Transición. Barcelona: Crítica, 2008,

Garcés, Joán. Allende y la experiencia chilena. Madrid: Siglo XXI, 2013.

Gómez Oliver, Miguel. "El movimiento estudiantil español durante el franquismo (1965-1975)" en Revista Crítica de Ciências Sociais, 81 (2008).

\footnotetext{
${ }^{81}$ Pérez Serrano, "Estrategias de la izquierda...” op cit., p. 124.
} 
Gracia Luño, Manuel. "Los movimientos sociales" en La lucha por la ruptura democrática en la Transición. 83-170. Madrid: Asociación por la memoria histórica del Partido del Trabajo de España, 2010.

-- "La fundación del nuevo partido: estrategia, táctica y línea de masas" en Pan, trabajo y libertad. Historia del Partido del Trabajo de España.71-139 Barcelona: El Viejo Topo, 2012.

Louça, Francisco y Rosas, Fernando. La (pen) última revolución de Europa. De la revolución de los claveles a la contrarrevolución neoliberal. Barcelona: Sylone, 2016.

Martín Ramos, José Luis. "Los orígenes de una nueva formación" en Pan, trabajo y libertad. Historia del Partido del Trabajo de España.17-62. Barcelona: El viejo topo, 2012.

Molano Bravo, José Luis. "Entrevista a Manuel Armenta", Amazonaws, 36:47, septiembre 2007, $\quad$ https://s3.eu-west3.amazonaws.com/memoriadelatransicion/Memoria + oral/Entrevistas $+30 \mathrm{PTA} / \mathrm{M}$ anuel+Armenta+Espejo.mp3.

Pérez Serrano, Julio. "Estrategias de la izquierda radical en el segundo franquismo y la Transición (1956-1982" en Chaput, Marie Claude; Pérez Serrano, Julio (eds.), La Transición española. Nuevos enfoques para un viejo debate.95-125 Madrid. Biblioteca Nueva, 2015.

-- "Orto y ocaso de la izquierda revolucionaria en España (1959-1994)" en QuirosaCheyrouze, Rafael (coord.), Los partidos en la Transición. Las organizaciones políticas en la construcción de la democracia en España. 249-289. Madrid: Biblioteca Nueva, 2013.

Rivera Pavón, Amador. "El Partido del Trabajo de España" en La lucha por la ruptura democrática en la Transición. 173-197. Madrid: Asociación por la memoria histórica del Partido del Trabajo de España, 2010.

Rodríguez López, Emmanuel. Por qué fracasó la democracia en España. Madrid: Traficante de sueños, 2015.

Rousset, Pierre. La revolutión chinoise. Tome 1: La Deumième révolution chinoise et la formation du projet maoiste. Amsterdam, Cuadernos del IIRF/IIRE, 1986.

Rupar, Brenda. "El debate chino-soviético y la emergencia del maoísmo como corriente política diferenciada en el Movimiento Comunista Internacional". Historia Contemporánea, 57 (2018).

Trotsky, León. La Internacional Comunista después de Lenin. Madrid: Akal, 1977.

Varela, Raquel. História do Povo na Revolução portuguesa: 1974-1975. Lisboa: Bertrand, 2014.

-- "El «eurocomunismo» de Santiago Carrillo y la «revolución democrática y nacional» de Cunhal: la política de los partidos comunistas en el final de las dictaduras en la Península Ibérica, 1974-1978”. https://dialnet.unirioja.es/servlet/articulo?codigo $=3312415$

Wilhelmi, Gonzalo. Romper el consenso. La izquierda radical en la Transición espalola (1975-1982). Madrid: Siglo XXI, 2016.

\section{FUENTES}

Archivo de la Transición (AT) 
Ernesto M. DíAz Macías

Mundo Obrero

Mundo Obrero Rojo

Hacia el Socialismo

El Correo Del Pueblo

La Voz de la Joven Guardia Roja de España

La Unión del Pueblo 